\title{
Use of Urea Wash ELISA to Distinguish Zika and Dengue Virus Infections
}

\section{Wen-Yang Tsai, Han Ha Youn, Jasmine Tyson, Carlos Brites, Jih-Jin Tsai, Celia Pedroso, Jan Felix Drexler, Angel Balmaseda, Eva Harris, Wei-Kung Wang}

Serologic testing remains crucial for Zika virus diagnosis. We found that urea wash in a Zika virus nonstructural protein $1 \mathrm{lgG}$ ELISA distinguishes secondary dengue from Zika virus infection with previous dengue (sensitivity $87.5 \%$, specificity $93.8 \%$ ). This test will aid serodiagnosis, serosurveillance, and monitoring of Zika complications in dengueendemic regions.

$\mathrm{T}$ he rapid spread of Zika virus and its association with fetal microcephaly and other birth defects (congenital Zika syndrome) present a pressing need for sensitive and specific diagnostic tests $(1,2)$. Centers for Disease Control and Prevention guidelines for laboratory diagnosis of Zika virus infection include a positive reverse transcription PCR as soon as possible after symptom onset to confirm Zika virus and a negative IgM test result to exclude Zika virus (3). Serologic testing remains a crucial component of Zika diagnosis because most Zika virus infections are asymptomatic, many persons seek Zika virus testing beyond the period during which RNA is detectable, and Zika virus can be transmitted sexually or after asymptomatic infection (1-3).

Zika virus belongs to the family Flaviviridae, in which several arboviruses, including the 4 serotypes of dengue virus (DENV-1-4), cause substantial disease in humans. Because of cross-reactivity of antienvelope antibody to Zika virus and other flaviviruses, positive or equivocal IgM results based on envelope protein require further testing with plaque-reduction neutralization tests (3-5). These tests can confirm acquisition of Zika virus as the first flavivirus infection (primary Zika virus [pZIKV] infection) but are

Author affiliations: University of Hawaii at Manoa, Honolulu, Hawaii, USA (W.-Y. Tsai, H.H. Youn, J. Tyson, W.-K. Wang); Federal University of Bahia, Salvador, Brazil (C. Brites, C. Pedroso); Kaohsiung Medical University, Kaohsiung, Taiwan (J.-J. Tsai); University of Bonn Medical Centre, Bonn, Germany (J.F. Drexler); National Center for Diagnosis and Reference, Ministry of Health, Managua, Nicaragua (A. Balmaseda); University of California at Berkeley, Berkeley, California, USA (E. Harris)

DOI: https://doi.org/10.3201/eid2407.171170 more challenging to interpret for those who have experienced previous flavivirus infections.

Several studies have demonstrated that DENVimmune serum and monoclonal antibodies can enhance Zika virus replication in vitro and in vivo (6-9) and raised concerns that previous DENV infection might increase the risk for and severity of congenital Zika syndrome. A recent study reported that a nonstructural protein 1 (NS1)-based blockade of binding ELISA can distinguish Zika virus and other flavivirus infections (10). However, it cannot distinguish pZIKV, Zika virus infection with previous dengue (DENV-ZIKV), and secondary DENV (sDENV) infections, which is critical in Zika virus- and DENV-endemic regions.

\section{The Study}

The Institutional Review Board of the University of Hawaii approved this study of coded serum or plasma samples (CHS \#17568, CHS \#23786). Convalescent-phase samples from patients with confirmed Zika virus infection who were either DENV-naive (designated as pZIKV panel) or previously exposed to DENV (designated as DENV-ZIKV panel) were from a cohort study in Nicaragua (11) (Table). Convalescent-phase samples from patients who had symptoms compatible with Zika virus infection and detectable anti-DENV IgG during the acute phase (probable DENVZIKV panel) came from Bahia, Brazil (12). Convalescentphase or post-convalescent-phase (3 months- 6 years after symptom onset) samples from patients who had confirmed primary DENV (pDENV) or sDENV infection came from Taiwan, Hawaii (USA), and Nicaragua; 12 flavivirus-naive samples had been previously described $(12,13)$.

The expression and purification of Zika virus NS1 protein (strain HPF2013) have been described (12). Purified DENV-1 NS1 protein was from the Native Antigen Company (Oxford, UK). NS1-IgG and NS1-IgM ELISAs as well as cutoff, positive, and negative controls in each plate have been described (12). The relative optical density (rOD) values were OD divided by the mean OD of positive controls. For the urea wash, we added $100 \mu \mathrm{L}$ urea $(4-8 \mathrm{~mol} / \mathrm{L})$ to each well at room temperature for $5 \mathrm{~min}$ between the second and third washings of NS1-IgG ELISA after the primary antibody (total 4 washings) (14). We used the 2-tailed Mann-Whitney test to determine $\mathrm{p}$ values comparing 2 groups (GraphPad Prism 6, https://www.graphpad.com/ scientific-software/prism). 
Table. Sampling time, serotype, and sources of serum/plasma panels in study of use of urea wash ELISA to distinguish Zika and dengue virus infections ${ }^{*}$

\begin{tabular}{|c|c|c|c|c|c|}
\hline $\begin{array}{l}\text { Panel sample collection } \\
\text { times }\end{array}$ & Category & $\begin{array}{l}\text { Sampling time after symptom } \\
\text { onset, mean (range) }\end{array}$ & $\begin{array}{c}\text { No. } \\
\text { patients }\end{array}$ & $\begin{array}{l}\text { Source (no. patients) and } \\
\text { year(s) of sample collection }\end{array}$ & Shown in \\
\hline \multicolumn{6}{|l|}{ Single time point } \\
\hline pDENV-1 & $\begin{array}{l}\text { Convalescent to } \\
\text { postconvalescent }\end{array}$ & $138(19-263) d$ & 16 & $\begin{array}{l}\text { Taiwan (4), 2001-2002; } \\
\text { Hawaii, USA (12), } 2015\end{array}$ & Figure 1 \\
\hline pZIKV & Convalescent & $17(14-24) d$ & 20 & Nicaragua, 2016 & Figure 1 \\
\hline sDENV & Convalescent & $14(8-35) d$ & 24 & Taiwan, 2001-2002 & Figure 1 \\
\hline DENV-ZIKV & Convalescent & $16(14-19) d$ & 20 & Nicaragua, 2016 & Figure 1 \\
\hline Probable DENV-ZIKV & Convalescent & $10(6-14) d$ & 19 & Brazil, 2015-2016 & Figure 1 \\
\hline sDENV & Postconvalescent & $3.2(3-4) \mathrm{mo}$ & 6 & $\begin{array}{l}\text { Taiwan (2), 2006-2009; } \\
\text { Nicaragua (4), 2006-2008 }\end{array}$ & Figure 2 \\
\hline sDENV & Postconvalescent & $12(12-12) \mathrm{mo}$ & 18 & Nicaragua, 2006-2008 & Figure 2 \\
\hline sDENV & Postconvalescent & 19.7 (18-24) mo & 14 & $\begin{array}{l}\text { Taiwan (10), 2006-2009; } \\
\text { Nicaragua (4), 2006-8 }\end{array}$ & Figure 2 \\
\hline sDENV & Postconvalescent & $71(67-72) \mathrm{mo}$ & 5 & Taiwan, 2006-2009 & Figure 2 \\
\hline $\begin{array}{l}\text { Sequential time points } \\
\text { sDENV }\end{array}$ & Postconvalescent & $10(3-18) \mathrm{mo}$ & 3 & Nicaragua, 2006-2008 & Figure 2 \\
\hline
\end{tabular}
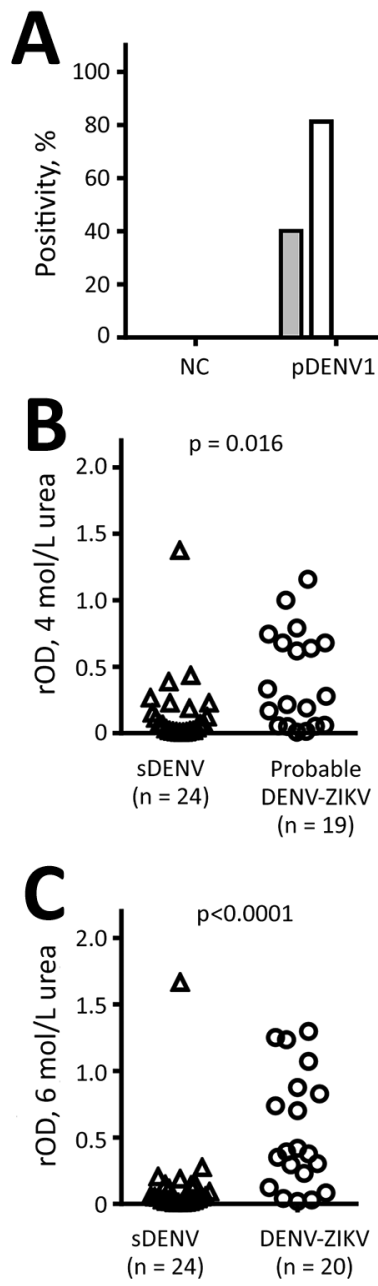
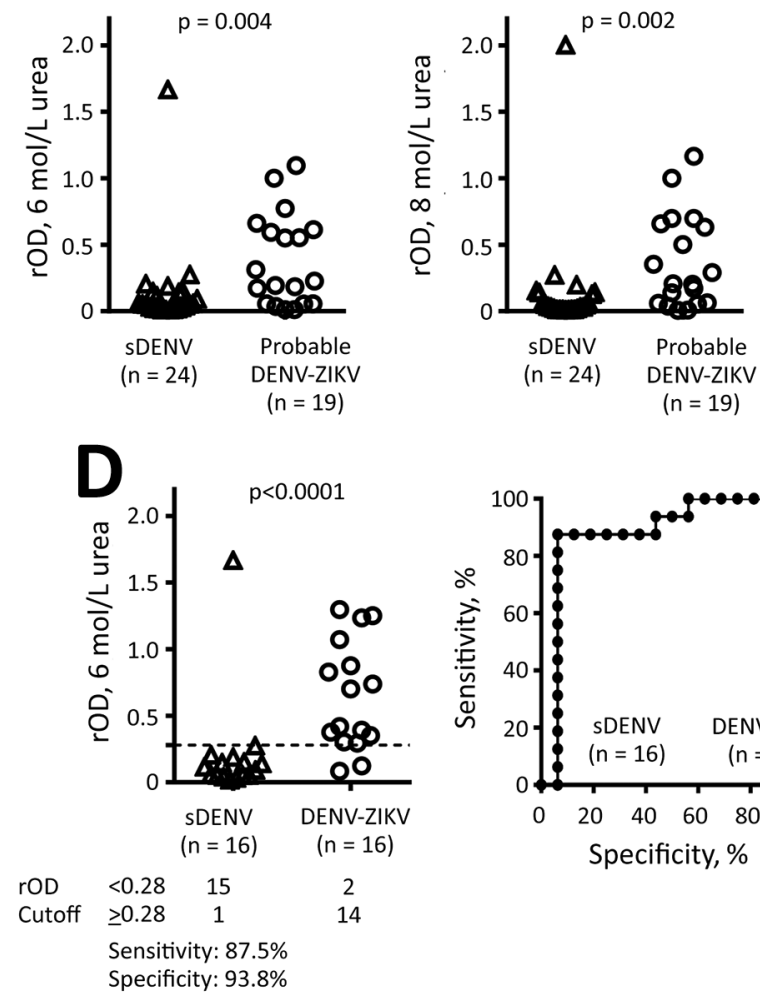

Figure 1. NS1 IgM and IgG ELISAs and urea wash in ZIKVNS1 IgG ELISA. A) Positivity rates for each panel. Only samples collected $<3$ months after symptom onset were tested for IgM. B) sDENV infection and probable DENV-ZIKV panels were tested with different concentrations $(4,6$, and $8 \mathrm{~mol} / \mathrm{L})$ of urea wash. C, D) sDENV and DENV-ZIKV panels were tested with $6 \mathrm{~mol} / \mathrm{L}$ urea wash: C) all samples; D) samples positive for both DENV-1-NS1 and ZIKVNS1 IgG ELISAs. Sensitivity and specificity are based on relative optical density cutoff at 0.28 (dashed line). Receiver-operating characteristics are shown in the graph on the right. Data are the mean of 2 experiments (each in duplicate). The 2-tailed Mann-Whitney test was used. DENV, dengue virus; DENV-ZIKV, confirmed Zika virus infection with previous exposure to DENV; NS1, nonstructural protein 1; pDENV1, primary DENV-1 infection; pZIKV, primary ZIKV infection; rOD, relative optical density; sDENV, secondary DENV infection; ZIKV, Zika virus. 
To evaluate convalescent-phase samples from pDENV1, pZIKV, sDENV, and DENV-ZIKV panels, we used 4 ELISAs. The primary DENV1 and pZIKV panels recognized their own NS1 without cross-reactivity (Figure 1, panel A; online Technical Appendix Table 1, https://wwwnc.cdc.gov/EID/article/24/7/17-1170Techapp1.pdf). The DENV-ZIKV panel recognized Zika virus and DENV NS1. The sDENV panel recognized not only DENV but also Zika virus NS1, especially in IgG ELISA, suggesting that cross-reactivity in NS1 IgG ELISA between SDENV and DENV-ZIKV panels is a challenge for NS1-based serologic tests for Zika virus infection.

We next investigated whether a urea wash in Zika virus NS1 IgG ELISA could distinguish SDENV and DENVZIKV infections. Different concentrations (4, 6, and 8 $\mathrm{mol} / \mathrm{L}$ ) of urea wash resulted in significantly lower rODs in the sDENV panel than in the probable DENV-ZIKV and DENV-ZIKV panels (Figure 1, panels B, C). We chose the 6 $\mathrm{mol} / \mathrm{L}$ urea wash for further analysis, considering its optimal cutoff value (data not shown). Comparing the samples with positive Zika virus- and DENV-1-NS1 IgG ELISA results (Figure 1, panel D), a cutoff rOD of 0.28 can distinguish the 2 panels with $87.5 \%$ sensitivity and $93.8 \%$ specificity.
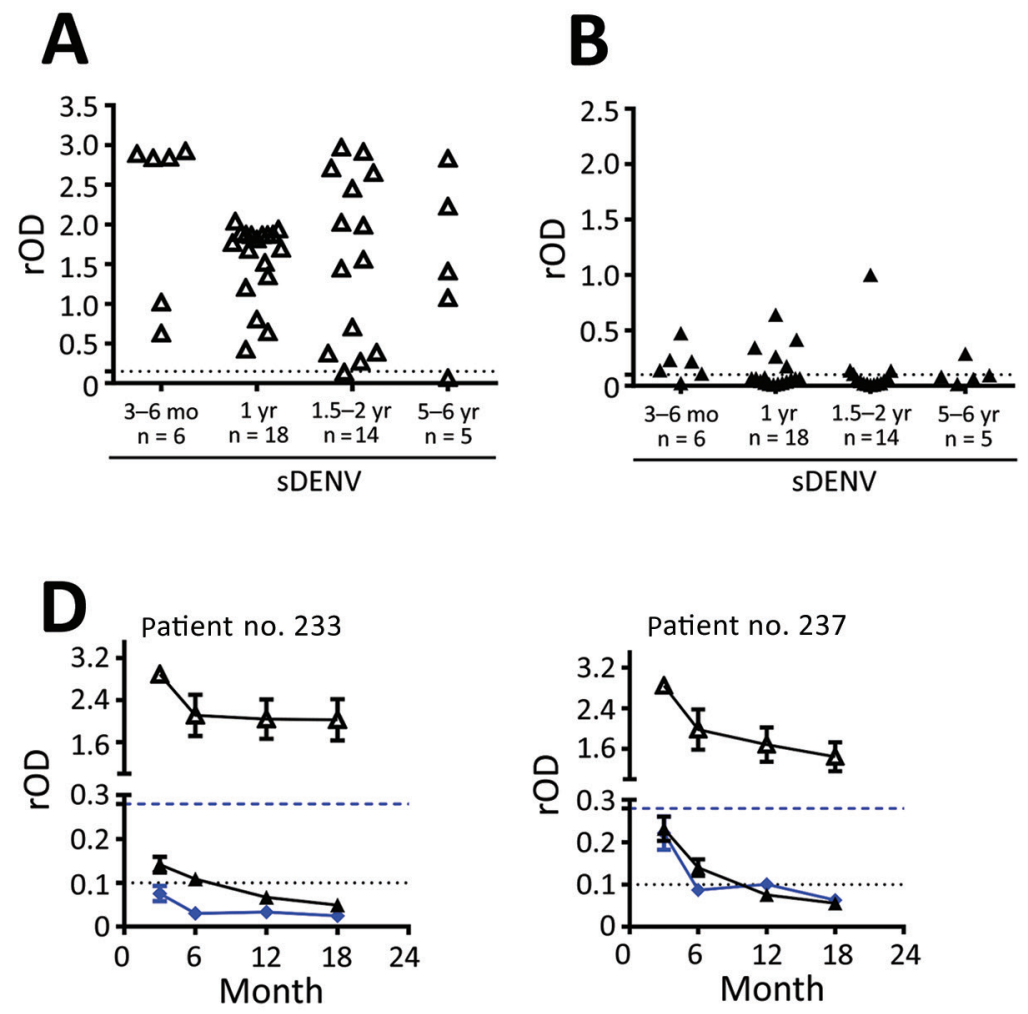

We further investigated whether a $6 \mathrm{~mol} / \mathrm{L}$ urea wash could reduce IgG cross-reactivity to ZIKV-NS1 by sDENV panel at later times. For the 43 post-convalescent-phase samples, positivity rates in DENV-1-NS1 IgG ELISAs decreased from $100 \%$ (3-6 months after symptom onset) to $80 \%$ (5-6 years) and for ZIKV-NS1 IgG ELISAs from $83.3 \%$ to $40 \%$, respectively (Figure 2, panels A, B). After 6 $\mathrm{mol} / \mathrm{L}$ urea wash in ZIKV-NS1 IgG ELISA, rOD decreased greatly, resulting in $4.7 \%$ having an $\mathrm{OOD} \geq 0.28$ (Figure 2, panel C). Results for sequential samples from 3 patients with sDENV infection (Figure 3, panel C) were generally consistent with the results from cross-sectional samples; rODs were all $<0.28$ after $6 \mathrm{~mol} / \mathrm{L}$ urea wash (Figure 2, panel D).

Although neutralization tests can confirm pZIKV infection, they remain difficult to interpret for patients who have previously experienced flavivirus infections, including sDENV and DENV-ZIKV infections. A recent study reported reduced cross-neutralization against Zika virus among samples from patients with sDENV infection $>6$ months after symptom onset; however, $23 \%$ still crossneutralized Zika virus (15). Our findings suggest that a 6 $\mathrm{mol} / \mathrm{L}$ urea wash in ZIKV-NS1 IgG ELISA can distinguish DENV-ZIKV and sDENV panels. It is conceivable that

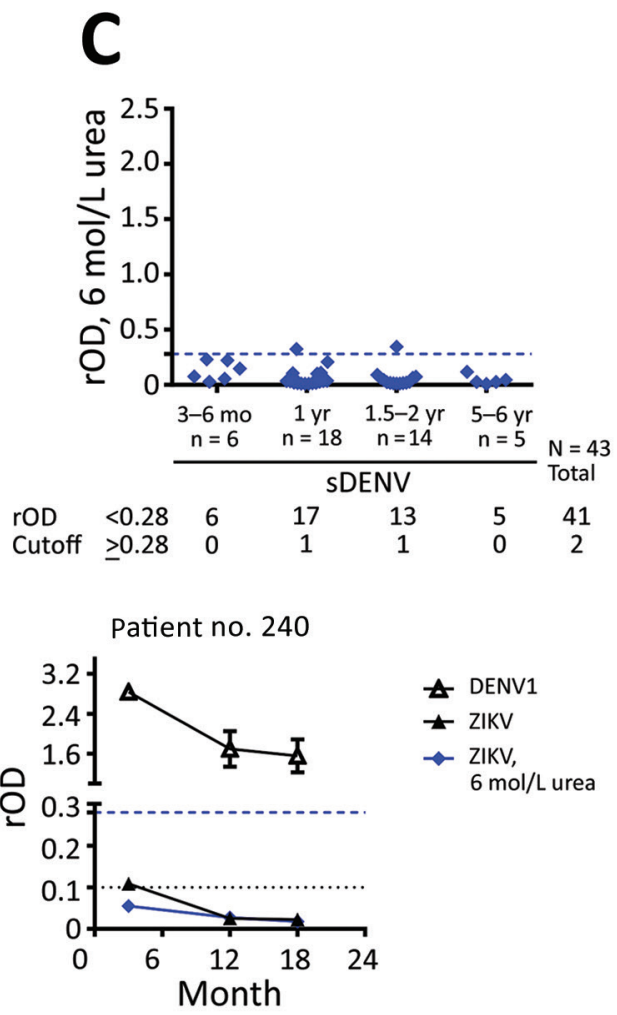

Figure 2. NS1 IgG ELISAs with urea wash for sDENV infection panel over time. A) DENV-1-NS1 IgG ELISA; B) ZIKV-NS1 IgG ELISA; and C) ZIKV-NS1 IgG ELISA with $6 \mathrm{~mol} / \mathrm{L}$ urea wash for SDENV samples collected from 3 months to 6 years after symptom onset. D) Sequentially collected samples from 3 patients with sDENV infection. Dotted lines indicate relative optical density cutoffs of ELISAs; dashed lines indicate rOD cutoff (0.28) of ELISA with $6 \mathrm{~mol} / \mathrm{L}$ urea wash. Data are expressed as mean \pm SD (for panel D) of 2 experiments (each in duplicate). The 2-tailed Mann-Whitney test was used. DENV, dengue virus; NS1, nonstructural protein 1; rOD, relative optical density; sDENV, secondary DENV infection; ZIKV, Zika virus. 
during sDENV infection, memory B cells recognizing NS1 residues that are conserved within the DENV serocomplex and between DENV and Zika virus expand greatly and generate high-avidity anti-NS1 antibodies through affinity maturation $(9,13)$. During Zika virus infection among those with previous DENV infection, memory B cells recognizing NS1 residues conserved between DENV and Zika virus will expand and generate high-avidity antibodies. Moreover, naive B cells recognizing Zika virus-specific NS1 residues will also expand; the combination of these 2 types of anti-NS1 antibodies may contribute to anti-NS1 antibodies with higher avidity, which remain bound after urea wash, compared with those from the sDENV panel (Figure 1, panel C; online Technical Appendix Figure 1).

This study has limitations. First, we tested only convalescent- and post-convalescent-phase samples. Second, the sample size in each panel was small; future studies with larger samples, including acute-phase and more sequential samples, are needed to validate these observations. Third, because our previous study showed cross-reactivity of antiDENV NS1 antibodies within the DENV serocomplex (5), we chose only DENV-1-NS1 IgG ELISA for this study; there was no difference in the positivity rates of DENV-1NS1 IgG ELISA between primary DENV-1 and sDENV-2 panels and between sDENV-1, sDENV-2, and sDENV-3 panels (online Technical Appendix Table 2). Fourth, given the global spread of Zika virus to regions where different flaviviruses are prevalent, development of serodiagnostic assays to distinguish Zika virus and other medically relevant flaviviruses remains to be explored.

\section{Conclusions}

Our method of combined ELISAs plus $6 \mathrm{~mol} / \mathrm{L}$ urea wash in Zika virus-NS1 IgG ELISA is simple, cost-effective, and applicable for use at field sites. This method could be used for routine serologic testing for Zika virus in dengue-endemic regions and for serosurveillance and Zika pregnancy studies to clarify epidemiology, transmission, and complications (1-3). Because congenital Zika syndrome may affect infants during growth and development, IgG-based NS1 ELISAs plus $6 \mathrm{~mol} / \mathrm{L}$ urea wash could be used in retrospective studies to elucidate the contribution of pZIKV infection alone or Zika virus infection with previous DENV to the full spectrum of congenital Zika syndrome $(1,2)$.

\section{Acknowledgments}

We thank David Clements for providing serum-free adapted S2 cells and Axel Lehrer for providing pMT-Bip plasmid.

This work was supported by grants R01AI110769-01 (W.-K.W.), R01 AI099631 and U54AI065359 (A.B.), and P01AI106695 and U19 AI1 18610 (E.H.) from the National Institutes of Health, National Institute of Allergy and Infectious Diseases; Molecular and Cellular Immunology Core through grant 5P30GM114737 from the National Institute of General Medical Sciences; and grant NHRI-106A1-MRCO-1017178 (J.-J.T., W.-K.W.) from the National Health Research Institutes, Taiwan. The funders had no role in study design, data collection and analysis, decision to publish, or preparation of the manuscript.

A US provisional patent application (no. 62/534,654), entitled Distinguish Zika and Dengue Virus Infection in ELISA, has been filed through the University of Hawaii.

\section{About the Author}

Dr. Tsai is a postdoctoral researcher at the Department of Tropical Medicine, Medical Microbiology and Pharmacology, John A. Burns School of Medicine, University of Hawaii at Manoa. His primary research interests include dengue virus, virus-like particles, and antibody responses to dengue virus and other flaviviruses.

\section{References}

1. Lessler J, Chaisson LH, Kucirka LM, Bi Q, Grantz K, Salje H, et al. Assessing the global threat from Zika virus. Science. 2016;353:aaf8160. http://dx.doi.org/10.1126/science.aaf8160

2. Aliota MT, Bassit L, Bradrick SS, Cox B, Garcia-Blanco MA, Gavegnano C, et al. Zika in the Americas, year 2: What have we learned? What gaps remain? A report from the Global Virus Network. Antiviral Res. 2017;144:223-46. http://dx.doi.org/ 10.1016/j.antiviral.2017.06.001

3. Centers for Disease Control and Prevention. Guidance for US laboratories testing for Zika virus infection [cited 2017 Feb 10]. http://www.cdc.gov/zika/laboratories/lab-guidance.html

4. Lanciotti RS, Kosoy OL, Laven JJ, Velez JO, Lambert AJ, Johnson AJ, et al. Genetic and serologic properties of Zika virus associated with an epidemic, Yap State, Micronesia, 2007. Emerg Infect Dis. 2008;14:1232-9. http://dx.doi.org/10.3201/ eid1408.080287

5. Lai CY, Tsai WY, Lin SR, Kao CL, Hu HP, King CC, et al. Antibodies to envelope glycoprotein of dengue virus during the natural course of infection are predominantly cross-reactive and recognize epitopes containing highly conserved residues at the fusion loop of domain II. J Virol. 2008;82:6631-43. http://dx.doi.org/10.1128/JVI.00316-08

6. Dejnirattisai W, Supasa P, Wongwiwat W, Rouvinski A, Barba-Spaeth G, Duangchinda T, et al. Dengue virus sero-cross-reactivity drives antibody-dependent enhancement of infection with Zika virus. Nat Immunol. 2016;17:1102-8. http://dx.doi.org/10.1038/ni.3515

7. Priyamvada L, Quicke KM, Hudson WH, Onlamoon N, Sewatanon J, Edupuganti S, et al. Human antibody responses after dengue virus infection are highly cross-reactive to Zika virus. Proc Natl Acad Sci U S A. 2016;113:7852-7. http://dx.doi.org/10.1073/ pnas.1607931113

8. Bardina SV, Bunduc P, Tripathi S, Duehr J, Frere JJ, Brown JA, et al. Enhancement of Zika virus pathogenesis by preexisting antiflavivirus immunity. Science. 2017;356:175-80. http://dx.doi.org/10.1126/science.aal4365

9. Stettler K, Beltramello M, Espinosa DA, Graham V, Cassotta A, Bianchi S, et al. Specificity, cross-reactivity, and function of antibodies elicited by Zika virus infection. Science. 2016;353:8236. http://dx.doi.org/10.1126/science.aaf8505

10. Balmaseda A, Stettler K, Medialdea-Carrera R, Collado D, Jin X, Zambrana JV, et al. Antibody-based assay discriminates Zika virus 
infection from other flaviviruses. Proc Natl Acad Sci U S A. 2017;114:8384-9. http://dx.doi.org/10.1073/ pnas. 1704984114

11. Kuan G, Gordon A, Avilés W, Ortega O, Hammond SN, Elizondo D, et al. The Nicaraguan pediatric dengue cohort study: study design, methods, use of information technology, and extension to other infectious diseases. Am J Epidemiol. 2009;170:120-9. http://dx.doi.org/10.1093/aje/kwp092

12. Tsai WY, Youn HH, Brites C, Tsai JJ, Tyson J, Pedroso C, et al. Distinguishing secondary dengue virus infection from Zika virus infection with previous dengue by combination of three simple serological tests. Clin Infect Dis. 2017;65:1829-36. http://dx.doi.org/10.1093/cid/cix672

13. Tsai WY, Durbin A, Tsai JJ, Hsieh SC, Whitehead S, Wang WK. Complexity of neutralization antibodies against multiple dengue viral serotypes after heterotypic immunization and secondary infection revealed by in-depth analysis of cross-reactive antibodies. J Virol. 2015;89:7348-62. http://dx.doi.org/10.1128/ JVI.00273-15

14. Puschnik A, Lau L, Cromwell EA, Balmaseda A, Zompi S, Harris E. Correlation between dengue-specific neutralizing antibodies and serum avidity in primary and secondary dengue virus 3 natural infections in humans. PLoS Negl Trop Dis. 2013;7:e2274. http://dx.doi.org/10.1371/journal.pntd.0002274

15. Collins MH, McGowan E, Jadi R, Young E, Lopez CA, Baric RS, et al. Lack of durable cross-neutralizing antibodies against Zika virus from dengue virus infection. Emerg Infect Dis. 2017;23:77381. http://dx.doi.org/10.3201/eid2305.161630

Address for correspondence: Wei-Kung Wang, University of Hawaii at Manoa, Department of Tropical Medicine, Medical Microbiology and Pharmacology, John A. Burns School of Medicine, 651 Ilalo St, BSB 325E, Honolulu, HI 96813, USA; e-mail: wangwk@hawaii.edu.

\section{April 2015: Emerging Viruses}

- Reappearance of Chikungunya, Formerly Called Dengue, in the Americas

- Hantavirus Pulmonary Syndrome, Southern Chile, 1995-2012

- Animal-Associated Exposure to Rabies Virus among Travelers, 1997-2012

- Evolution of Ebola Virus Disease from Exotic Infection to Global Health Priority, Liberia, Mid-2014

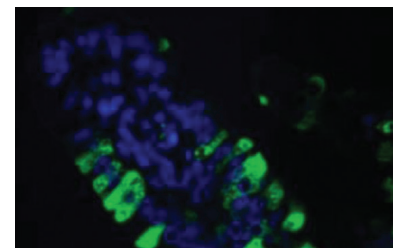

- Population Structure and Antimicrobial Resistance of Invasive Serotype IV Group B Streptococcus, Toronto, Ontario, Canada

- Sequence Variability and Geographic Distribution of Lassa Virus, Sierra Leone
- Norovirus Genotype Profiles Associated with Foodborne

Transmission, 1999-2012

- Deaths Associated with Respiratory Syncytial and Influenza Viruses among Persons $>5$ Years of Age in HIVPrevalent Area, South Africa, 1998-2009

- Influenza A(H7N9) Virus Transmission between Finches and Poultry

- Highly Pathogenic Avian Influenza $\mathrm{A}(\mathrm{H} 5 \mathrm{~N} 1)$ Virus Infection among Workers at Live Bird Markets, Bangladesh, 2009-2010

- Increased Risk for Group B Streptococcus Sepsis in Young Infants Exposed to HIV, Soweto, South Africa, 2004-2008

- Influenza A(H1ON7) Virus in Dead Harbor Seals, Denmark
- La Crosse Virus in Aedes japonicus japonicus Mosquitoes in the Appalachian Region, United States

- Pathogenicity of 2 Porcine Deltacoronavirus Strains in Gnotobiotic Pigs

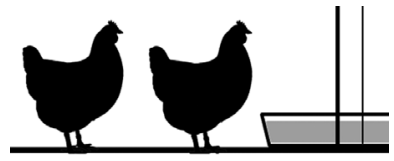

- Multidrug-Resistant Salmonella enterica Serotype Typhi, Gulf of Guinea Region, Africa

- Reassortant Avian Influenza A(H9N2) Viruses in Chickens in Retail Poultry Shops, Pakistan, 2009-2010

- Candidate New Rotavirus Species in Sheltered Dogs, Hungary

- Severity of Influenza $\mathrm{A}(\mathrm{H} 1 \mathrm{~N} 1)$ Illness and Emergence of D225G Variant, 2013-14 Influenza Season, Florida, USA
- Close Relationship of Ruminant Pestiviruses and Classical Swine Fever Virus

- Peste des Petits Ruminants Virus in Heilongjiang Province, China, 2014

- West Nile Virus Infection Incidence Based on Donated Blood Samples and Neuroinvasive Disease Reports, Northern Texas, USA, 2012

- Spotted Fever and Scrub Typhus Bacteria in Patients with Febrile Illness, Kenya

- Virus Antibodies, Israel, 2009-2010

- Outbreak of Severe Zoonotic Vaccinia Virus Infection, Southeastern Brazil

- Lack of Middle East Respiratory Syndrome Coronavirus Transmission from Infected Camels 